\title{
CURVA DE CRESCIMENTO E ANÁLISE BIOQUÍMICA EM EXPLANTES FOLIARES DE Poincianella pyramidalis [TUL.] L.P. QUEIROZ.
}

\section{Rosembrando S. L. Carvalho Filho'; Tecla dos Santos Silva²; Tamara Torres $\operatorname{Tanan}^{3}$ e José Raniere Ferreira de Santana ${ }^{4}$}

1. Bolsista PIBIC/CNPq, Graduando em Agronomia, Universidade Estadual de Feira de Santana, Laboratório de Cultura de Tecidos Vegetais, Unidade Experimental Horto Florestal, e-mail: carvalhoea@yahoo.com

2. Bióloga, MSc. em Biotecnologia, Dra. em Recursos Genéticos Vegetais, Universidade Estadual de Feira de Santana, Laboratório de Cultura de Tecidos Vegetais, Unidade Experimental Horto Florestal, e-mail: silva.stecla@gmail.com 3. Bióloga, MSc. em Recursos Genéticos Vegetais, Doutoranda em Recursos Genéticos Vegetais, Universidade Estadual de Feira de Santana, Laboratório de Germinação, Unidade Experimental Horto Florestal, email: tamara.tanan @ yahoo.com.br 4. Orientador, Departamento de Ciências Biológicas, Universidade Estadual de Feira de Santana e-mail: jose.raniere@gmail.com

PALAVRAS-CHAVE: Catingueira. Cultivo in vitro. Bioquímica.

\section{INTRODUÇÃO}

A espécie Poincianella pyramidalis [Tul.] L.P.Queiroz, sinonímia Caesalpinia pyramidalis [Tul.] pertencente à família Fabaceae, é conhecida popularmente como catingueira, catinga-de-porco, pau-de-porco e pau-de-rato (MAIA, 2012). Sua madeira é utilizada como fonte de lenha, carvão, estacas, podendo também ser utilizada para restauração florestal e como fonte de feno para alimentação animal, possuindo ainda utilização medicinal popular, cujas flores, folhas e cascas são utilizadas no tratamento das infecções catarrais e diarreias (MAIA, 2012). O uso dos seus recursos pode impedir sua reprodução natural, ocasionando problemas com a propagação, o que pode contribuir para o risco de extinção. Diante disso, faz-se necessário a elaboração de estratégias para sua multiplicação, conservação e manejo sustentável. Neste sentido, a utilização de recursos como técnicas de cultura de tecidos vegetais, tem auxiliado na propagação clonal de genótipos de várias espécies lenhosas. Dentre as técnicas da cultura de tecidos, tem-se a micropropagação que se trata de uma técnica que permite a obtenção em curto espaço de tempo e em qualquer época do ano, de grande número de plantas com qualidade fitossanitária (NAGAO, PASQUAL, RAMOS. 1994); podendo ser realizada por duas vias: organogênese ou embriogênese somática (PASQUAL et al., 1997), das quais podem ser obtidas diretamente do explante ou indiretamente, por intermédio da formação de calos. No processo de desenvolvimento in vitro, o calo passa por diferentes fases que resultam em mudanças em sua morfologia, dentre as quais pode-se identificar os fatores relacionados à sua friabilidade ou desenvolvimento de embriões somáticos (VASCONCELOS et al., 2012). A identificação destas fases é feita através da construção da curva de crescimento de calos, onde é possível avaliar os processos fisiológicos fundamentais que influenciam no crescimento destes. $\mathrm{Na}$ obtenção dos processos morfogênicos in vitro, são utilizados reguladores de crescimento vegetal, como citocininas e auxinas, em que $\mathrm{o}$ balanço entre as concentrações dos mesmos são fatores determinantes para o desenvolvimento da planta in vitro (PIZA et al., 2001). Nesse contexto, objetivou-se estudar a curva de crescimento de calos em $P$. pyramidalis, assim como analisar bioquimicamente os calos obtidos.

\section{METODOLOGIA}

Para a construção da curva de crescimento foram utilizados explantes foliares $\left( \pm 0,5 \mathrm{~cm}^{2}\right)$ de $P$. pyramidalis que foram inoculados em placas de Petri contendo $30 \mathrm{ml}$ de meio de cultura MS (MURASHIGE; SKOOG, 1962), suplementado com 5,0 $\mu \mathrm{M}$ de BAP. Essa curva foi determinada pela quantificação da massa fresca (mg) dos explantes com calos, a partir do dia "zero" (explantes antes da inoculação) até 56 dias, em intervalos de 7 dias, totalizando 9 períodos.

O percentual de crescimento dos calos foi determinado por meio da equação: $\mathrm{Pf}-\mathrm{Pi} / \mathrm{Pf}$ x 100, onde $\mathrm{Pi}=$ Peso inicial e $\mathrm{Pf}=$ Peso final de calos (LAMEIRA, 1997 apud SOUSA, 2015). As amostras para a determinação de carboidratos foram retiradas em cada período de incubação (em intervalos de 7 dias), contados a partir do dia "zero" (explantes antes da inoculação). 
A quantificação bioquímica foi baseada na metodologia descrita por Nogueira et al. (2007) com modificações. Para determinação dos açúcares redutores (AR) e açúcares solúveis totais (AST), foram utilizados $100 \mathrm{mg}$ de explantes frescos (com e sem calos) macerados com auxílio de almofariz e pistilo em $10 \mathrm{~mL}$ de água destilada. Em seguida foram colocados em tubo de centrífuga e permaneceram em banho-maria à temperatura de $40^{\circ} \mathrm{C}$ por 30 minutos e logo após, foram centrifugados a $3000 \mathrm{rpm}$ por 15 minutos a $25^{\circ} \mathrm{C}$. O sobrenadante foi recolhido e congelado $\left( \pm-6^{\circ} \mathrm{C}\right)$ para posterior análise. A quantificação dos AST foi realizada pelo método de Antrona (YEMM; WILLIS, 1954) e do AR pelo método do DNS (MILLER,1959), utilizando solução de glicose como padrão. A leitura da absorbância foi realizada em espectrofotômetro Uv-Vis a $540 \mathrm{~nm}$ para AR e 620 $\mathrm{nm}$ para AST. O equipamento foi zerado com o branco $(0,5 \mathrm{~mL}$ de água destilada no lugar da amostra) sendo a quantificação baseada em curva padrão para glicose. As concentrações de sacarose foram determinadas pela diferença entre os teores de açúcares solúveis totais e açúcares redutores, multiplicada pelo fator 0,95 (MARTIM, 2003). Foram utilizadas quatro repetições, sendo cada repetição constituída por cinco unidades experimentais (cinco calos).

\section{RESULTADOS E DISCUSSÃO}

A curva de crescimento apresentou padrão sigmoidal, com três fases distintas: lag, exponencial e linear (Figura 1). A fase lag ocorreu até o $35^{\circ}$ dia de cultivo, cuja taxa de crescimento foi de $85,06 \%$. Nesta fase, tendo em vista o elevado percentual de crescimento em detrimento das fases seguintes, verifica-se que as células do tecido vegetal se prepararam para intensa divisão celular, acumulando biomassa (SANTOS, et al., 2003); O período de fase lag varia de acordo a espécie em estudo, Santos et al. (2009) estudaram o comportamento da curva de crescimento de calos em café conilon (Coffea canephora Pierre) e identificaram que a fase lag ocorreu até o $10^{\circ}$ dia de inoculação equivalente a $57 \%$ de crescimento utilizando segmento foliar. A fase exponencial foi identificada entre o $35^{\circ}$ e $49^{\circ}$ dia de cultivo, apresentando um crescimento de $81,35 \%$ (Figura 1), oposto ao verificado por Nogueira et al. (2008) que analisando a curva de crescimento em explantes foliares de muricipequeno (Byrsonima intermedia A. Juss.) perceberam que a fase exponencial se estendeu do $20^{\circ}$ ao $40^{\circ}$ dia de cultivo, com $88 \%$ de crescimento. Esta fase é considerada como o período ao qual ocorre máxima divisão celular e acumulo de matéria seca (STEIN et al., 2010). Já a fase linear é identificada como o período onde há redução da divisão celular e aumento da área celular (SANTOS et al., 2003), a qual, no presente trabalho durou 7 dias (dos 56 dias de cultivo) e apresentou 69,85\% de crescimento (Figura 1). Silva (2017) estudando o comportamento de calos provenientes de explantes foliares de aroeira-do-sertão (Myracrodruon urundeuva Fr. All.) observou a fase linear entre o $28^{\circ}$ e o $35^{\circ}$ dia da inoculação, cujo percentual de crescimento foi de $40,95 \%$.

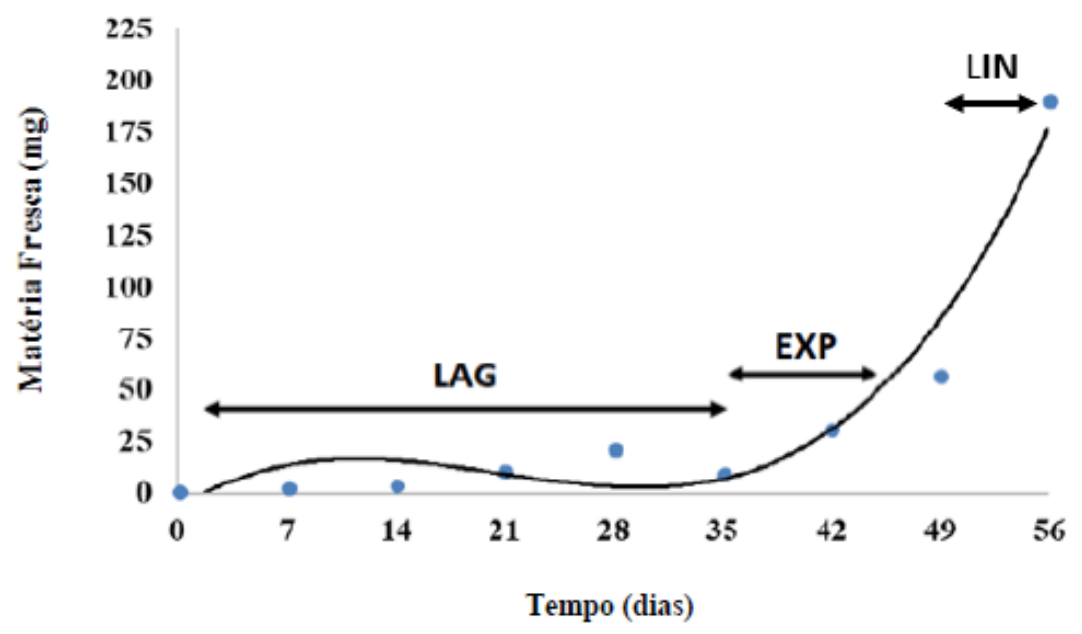

Figura 1: Curva de crescimento de calos formados a partir de explantes foliares de Poincianella pyramidalis [Tul.] L.P.Queiroz inoculados em meio de cultura MS suplementado com 5,0 $\mu \mathrm{M}$ de BAP durante 56 dias de incubação exibindo distintas fases: Fase LAG, Fase EXP (exponencial) e Fase LIN (linear). Feira de SantanaBA, 2018. 
A quantificação do conteúdo de carboidratos dos calos de $P$. pyramidalis foi realizada durante 56 dias de cultivo e foi possível detectar açúcares redutores (AR), sacarose e açúcares solúveis totais (AST) (Figura 2). O conteúdo de carboidratos verificado no dia da inoculação, é certamente oriundo dos açúcares contidos na folha da planta-mãe doadora de explantes, somados a sacarose disponibilizada à planta no meio de cultura (NOGUEIRA et al. 2008). O conteúdo de AR foi observado no período que compreendeu a fase lag da curva de crescimento, apresentando um comportamento decrescente ao longo do tempo de cultivo até o $21^{\circ}$ dia, onde posteriormente houve um incremento ( $28^{\circ}$ dia). Após o $35^{\circ}$ dia de cultivo não foi possível quantificar níveis de AR pelo método adotado, provavelmente porque o que era produzido estava sendo prontamente consumido em função das demandas celulares. Esta queda de AR ao longo do período de cultivo foi semelhante ao observado por Nogueira et al. (2008) ao qual sugeriram que os calos de murici-pequeno utilizaram somente a reserva de açúcares redutores contida no explante no dia da inoculação, originada da plantamãe. A redução nos teores de açúcares redutores também foi observada por Serra et al. (2000) em explantes foliares em castanha-do-brasil (Bertholletia excelsa H. B. K.), no qual constatou que no período de 30 dias após a inoculação, a redução dos açúcares redutores mostrou-se acentuada, chegando a um nível equivalente a $20 \%$ do valor inicial, coincidindo com a fase lag de crescimento cujos calos se preparam para o início da fase exponencial e que, portanto, essa redução se deu possivelmente pela necessidade de produção de energia a ser utilizada na fase exponencial, a qual é caracterizada pelo aumento na divisão celular resultando no maior percentual de crescimento (SERRA et al., 2000).

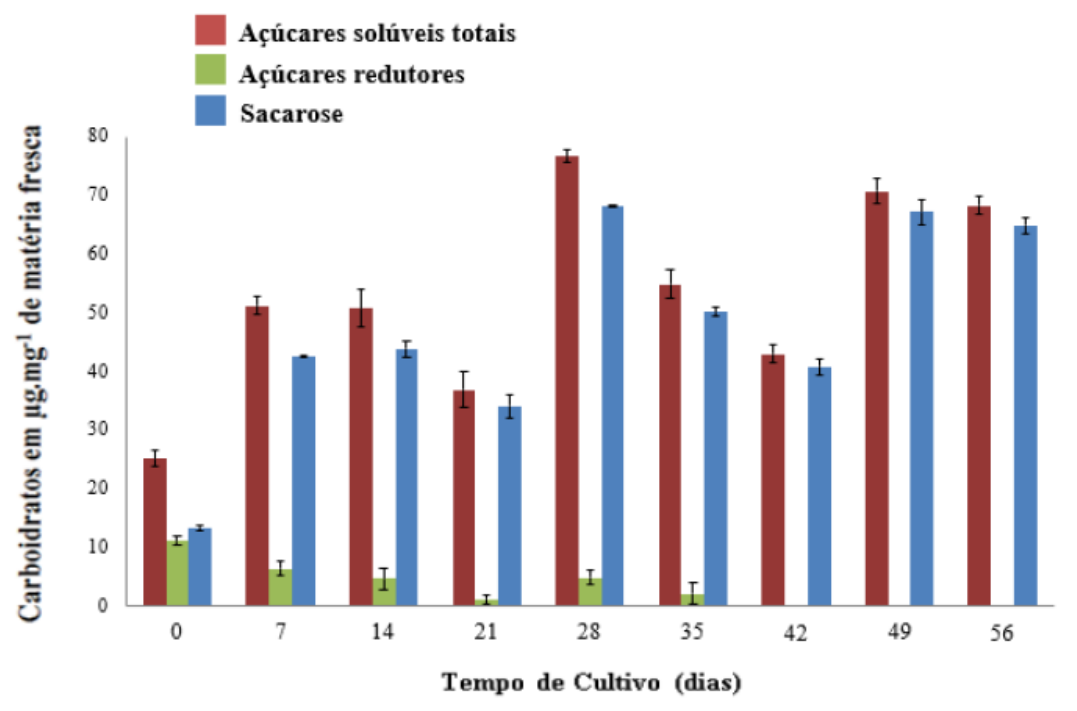

Figura 2: Conteúdo de carboidratos dos calos de Poincianella pyramidalis [Tul.] L.P.Queiroz formados a partir de explantes foliares inoculados em meio de cultura MS suplementado com 5,0 $\mu \mathrm{M}$ de BAP, durante 56 dias de incubação (média \pm desvio padrão, n= 4). Feira de Santana-BA, 2018.

O nível máximo de sacarose e AST foram detectadas aos 28 dias de cultivo (Figura 2). Segundo Santos et al. (2010), os carboidratos fornecem esqueletos de carbono e energia para a biossíntese de compostos orgânicos envolvidos no metabolismo celular, isso pode explicar o que provavelmente aconteceu no período de transição da fase lag à fase exponencial, tendo em vista a necessidade de carboidratos como fonte de energia.

Em calos de murici-pequeno (Byrsonima intermedia A. Juss.) durante 120 dias de cultivo, Nogueira et al. (2008) obtiveram o segundo maior nível de AST aos 70 dias, e atribuíram tais resultados à absorção da glicose e frutose contidas em pequenas quantidades no meio de cultura e obtidas pela quebra da sacarose durante a autoclavagem. O estudo do conteúdo de carboidratos é de fundamental importância quando objetiva-se compreender as alterações bioquímicas nas diferentes fases de crescimento dos calos, possibilitando inferir sobre possíveis comportamentos que demandam 
energia como por exemplo as divisões celulares, formação de embriões ou a produção de metabolitos secundários.

\section{CONCLUSÃO}

A curva de crescimento dos calos de $P$. pyramidalis apresenta forma sigmoidal com três fases distintas (lag, exponencial e linear) em 56 dias de cultivo.

Os açúcares redutores apresentam comportamento decrescente durante o período de estudo, não sendo verificados a partir do $35^{\circ}$ dia de cultivo.

O conteúdo de sacarose e açúcares solúveis totais possuem comportamentos que variam em função das fases de crescimento dos calos in vitro.

\section{REFERÊNCIAS}

MAIA, G. N. Caatinga: árvores e arbustos e suas utilidades. 2.ed. Printcolor Gráfica e Editora, Fortaleza, 2012. 413 p.

MARTIM, S. A. Pulverização do cafeeiro com açúcar: potencial de uso em mudas submetidas a deficiência hídrica e na recuperação de plantas atingidas por Glyphosate. Dissertação (Mestrado em Fisiologia Vegetal) - Universidade Federal de Lavras, Lavras. 67p. 2003.

MURASHIGE, T; SKOOG, F. A revised medium for rapid growth and bioassays with tobacco tissue cultures. Physiology Plant. 15:473-497. 1962.

NAGAO, E. O; PASQUAL, M; RAMOS, J. D. Efeitos da sacarose e do nitrogênio inorgânico sobre a multiplicação "in vitro" de brotações de porta-enxerto de citros. Bragantia, Campinas; v. 53, n. 1, p. 25-31, 1994.

NOGUEIRA, R. C. et al. Curva de crescimento e análises bioquímicas de calos de murici-pequeno (Byrsonima intermedia A. Juss.). Revista Brasileira de Plantas Medicinais, Botucatu, v.10, n.1, p.44-48, 2008.

PASQUAL, M.; HOFFMANN, A.; RAMOS, J. D. Cultura de tecidos vegetais: Tecnologia e aplicações. Lavras: UFLA/FAEP, p. 7-45. 1997.

PIZA, I. M. T.; LIMA, G. P. P.; BRASIL, O. G. Reguladores vegetais na micropropagação de abacaxizeiro. Revista Ceres. Viçosa, v. 48, n. 280, p. 681-690. 2001.

SOUSA, F. P. Micropropagação de de Hyptis ramosa Pohl ex Benth. (Lamiaceae). 2015. 64f. Dissertação (Mestrado em Recursos Genéticos Vegetais). Universidade Estadual de Feira de Santana.

VASCONCELOS, J. N. C, et al. Indução, caracterização bioquímica e ultra-estrutural de calos de aroeira-do-sertão (Myracrodruon urundeuva Fr. All.) Revista Brasileira de Plantas Medicinais., Botucatu, v.14, n.4, p.592-597, 2012.

YEMM, E. W.; WILLIS, A.J. The estimation of carbohydrates in plant extracts by anthrone. The Biochemical Journal, v. 57, p. 508-514, 1954.

MILLER, G. L. Use of dinitro salicylic acid reagent for determination of reducing sugar. Analytical Biochemistry, New York, v. 31, n. 3, p. 426-428, 1959.

NOGUEIRA, R. C. et al. Indução de calos em explantes foliares de murici-pequeno (Byrsonima intermedia A. Juss.). Ciência e Agrotecnologia, Lavras; v. 31, n. 2, p. 366-370, 2007.

SANTOS, C. G. et al. Indução e Análise Bioquímica de Calos obtidos de segmentos foliares de Coffea arabica (L., CULTIVAR RUBI). Ciência e agrotecnologia, Lavras. V.27, n.3, p.571-577, 2003.

SANTOS, D. N. et al. Análise bioquímica de calos de pinhão-manso. Revista Ciência Rural, Santa Maria, v.40, n.11, p. 2268-2273, 2010.

SANTOS, M. R. A; FERREIRA, M. G. R; SARUBO, V. Determinação da curva de crescimento de calos em café conilon (Coffe canephora PIERRE). In: VI Simpósio de Pesquisa dos Cafés do Brasil. 25., 2009. Consorcio Pesquisa Café. Anais. Vitoria-ES.

SERRA, A. G. P; PAIVA, R; PAIVA, P. D. O. Análises bioquímicas de calos formados de explantes foliares de castanha-do-brasil (Bertholletia excelsa H. B. K.). Revista Ciência e Agrotecnologia., Lavras, v. 24, n. 4, p. 833-840, 2000.

SILVA, T. S. Morfogênese e Conservação in vitro de Caesalpinia pyramidalis Tul. 2012. 87f. (Dissertação - Mestrado). Feira de Santana: Universidade Estadual de Feira de Santana (UEFS).

STEIN, V. C. et al. Curva de crescimento e índice de divisão celular de calos de Ingazeiro. Revista Ciências Agrarias. v.53, n.2, p.159-163, 2010. 